Technological University Dublin

ARROW@TU Dublin

\title{
Comparison Between Gelatines Extracted From Mackerel and Blue Whiting Bones after Different Pre-treatments
}

\author{
Catherine Barry-Ryan \\ Technological University Dublin, Catherine.Barryryan@tudublin.ie \\ Zied Khiari \\ Technological University Dublin \\ Daniel Rico \\ Public University Nevarra, Pamplona, Spain
}

See next page for additional authors

Follow this and additional works at: https://arrow.tudublin.ie/schfsehart

Part of the Food Chemistry Commons

\section{Recommended Citation}

Barry-Ryan, C., Khiari, Z., Rico, D., Martin-Diana, A., : Comparison Between Gelatines Extracted From Mackerel and Blue Whiting Bones after Different Pre-treatments, Food Chemistry, Vol.139, Issues 1-4, 15 August 2013, pp. 347-354, doi.org/10.1016/j.foodchem.2013.01.017.

This Article is brought to you for free and open access by the School of Food Science and Environmental Health at ARROW@TU Dublin. It has been accepted for inclusion in Articles by an authorized administrator of ARROW@TU Dublin. For more information, please contact arrow.admin@tudublin.ie, aisling.coyne@tudublin.ie, gerard.connolly@tudublin.ie.

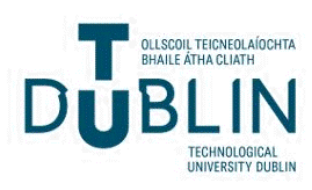


Authors

Catherine Barry-Ryan, Zied Khiari, Daniel Rico, and Ana Belen Martin-Diana

This article is available at ARROW@TU Dublin: https://arrow.tudublin.ie/schfsehart/111 
1 Comparison between gelatines extracted from mackerel and blue whiting bones

3

4 Zied Khiari* $^{1}$, Daniel Rico ${ }^{2}$, Ana Belen Martin-Diana ${ }^{3}$ and Catherine Barry-Ryan ${ }^{1}$. 5

$6 \quad{ }^{1}$ School of Food Science and Environmental Health, Dublin Institute of Technology 7 (DIT), Cathal Brugha Street, Dublin 1, Ireland.

8

$9 \quad{ }^{2}$ Food Technology Department, Public University Nevarra, Pamplona, Spain. 10

$11{ }^{3}$ Agricultural Technological Institute of Castilla and Leon, Government of Castilla 12 and Leon, Finca Zamadueñas, Valladolid, Spain.

13

$14 *$ Corresponding author/Present address: Zied Khiari, Department of Agricultural 15 Food \& Nutritional Science (AFNS). 4-10, Agriculture/Forestry Centre. University of 16 Alberta. Edmonton, AB, Canada T6G 2P5.

$17 \quad$ Tel: +17804924614 .

18 Email: khiari@ualberta.ca

19

20

21 

1 3

\section{Abstract}

Gelatines were extracted from mackerel and blue whiting bones after chemical or enzymatic pre-treatments and their functional properties (solubility, foaming and emulsifying properties) were analysed. The pre-treatment significantly $(p<0.05)$ affected the composition and the functional properties of the extracted gelatines. The amino acid analyses showed that chemically pre-treated bone gelatines had higher imino acids (proline and hydroxyproline) contents compared to those extracted after the enzymatic pre-treatment, regardless of the fish species. It was observed that all gelatines had higher solubility at low $\mathrm{pH}$ with a maximum value observed at $\mathrm{pH} 2$. A significant effect of ionic strength was observed. Increasing the $\mathrm{NaCl}$ concentration to more than $1 \%$ resulted in a significant decrease of the solubility. Mackerel bone gelatines showed lower foaming capacity (FC) and higher foaming stability (FS) than blue whiting bone gelatines. Increasing the concentration of gelatine decreased the emulsifying activity (EAI) but increased the stability (ESI) indices. The use of enzymes in the pre-treatment process generated gelatines with significantly $(\mathrm{p}<0.05)$ higher EAI and ESI.

Key words: mackerel, blue whiting, bones, gelatines.

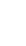
2 4 5 6 


\section{Introduction}

Every year, significant amounts of waste are generated by the fish processing industries. These wastes are regarded as low quality products and are discarded or in the best case scenario processed into fishmeal and pet food (Kim \& Mendis, 2006). Fish waste is costly to dispose of and is typically discarded overboard in case of onboard processing or buried to landfill for the on-shore processing.

Environmental legislation has contributed to the introduction of sustainable waste management practices in the European Union. The European Directive 1999/31/EC on the landfill of waste (Council Directive, 1999) and the Regulation (EC) No 1774/2002 restrict the disposal of untreated organic waste not intended for human consumption. Therefore more sustainable alternatives are needed. Recycling fish waste is of interest from an environmental point of view by reducing the organic contaminant charge. Recent advances in fish waste management have resulted in their examination as a source of ingredients with a potential application to the food industry. Underutilised fish species along with fish processing discards may be potential sources of bioactive and functional ingredients such as gelatine (Shahidi, 1994).

Gelatine is a biopolymer produced by extraction and hydrolysis of fibrous, insoluble collagen. Sources for fish collagen can be fish skin, bones, scales or connective tissue (Kim \& Mendis, 2006). The industrial process of gelatine manufacture involves either an acid or alkaline pre-treatment followed by extraction with warm water. The heat denaturation converts collagen into gelatine. Further clarification steps include filtration, concentration, drying and milling (Schrieber \& Gareis, 2007). The quality of gelatine preparation depends on its physicochemical 
71 properties, which are influenced not only by the species or tissue from which it is extracted, but also by the severity of pre-treatment and extraction process.

Atlantic mackerel (Scomber scombrus) is a pelagics species and is abundant in cold and temperate shelf areas such as the North Atlantic Ocean (Collette \& Nauen, 1983). The world catch of mackerel was estimated around 566 thousand tonnes in 2007 (FAO, 2009). Blue whiting (Micromesistius poutassou) is a typical lean species and belongs to the Gadidae family along with cod and haddock. Blue whiting is an underutilised fish with a global catch estimated to be about 1.7 thousand tonnes in 2007 (FAO, 2009).

In this study, mackerel and blue whiting, models for oily and white fish, respectively, were investigated for gelatines extraction. The effect of the pre-treatment of fish bones on the composition and functional properties of gelatines was evaluated.

\section{Materials and methods}

\subsection{Materials}

Atlantic mackerel (Scomber scombrus) caught in early March 2007, were kindly provided by Bord Iascaigh Mhara (BIM, Ireland). Blue whiting (Micromesistius poutassou) caught in January 2008, were provided by Donegal Seafood. Both fish were caught in the area FAO 27 (Atlantic, Northeast). The average weights for mackerel and blue whiting were $277 \mathrm{~g}$ and $116.8 \mathrm{~g}$, respectively. Fillets were manually removed after beheading and evisceration of fish, the remaining meat was separated from the frame using a knife. Bones and scales were cut manually into small pieces (1 to $2 \mathrm{~cm}$ length) using scissors. The bones were divided into batches and kept in the freezer at - $20^{\circ} \mathrm{C}$ for less than one month before use. All chemicals used were analytical grade. 


\subsection{Enzymes}

Flavourzyme is a fungal protease/peptidase complex obtained from Aspergillus oryzae. Flavourzyme had a declared activity of 500 leucine aminopeptidase units (LAPU)/g), where one LAPU is defined as the amount of enzyme which hydrolyzes $1 \mu \mathrm{mol}$ of L-Ieucine-p-nitroanilide per minute. Alcalase is an alkaline enzyme produced by Bacillus licheniformis. Alcalase had an activity of 2.4 Anson units (AU)/g, where one Anson unit is defined by Aspmo et al. (2005) as the amount of enzyme that releases $1.0 \mathrm{mEq}$ of tyrosine from urea-denatured hemoglobin per minute. Flavourzyme was produced by DSM Nutritional Products, Inc. (Kaiseraugst, Switzerland) and Alcalase was produced by Novozyme Co. (Copenhagen, Denmark). Both enzymes were supplied by Sigma-Aldrich, Inc. (Dublin, Ireland).

\subsection{Proximate analysis of fish bones}

The proximate analysis was carried out according to the procedures of the Association of Official Analytical Chemists (AOAC, 2000). Protein content was determined by the Kjeldahl method using an automatic Kjeldahl system (Gerhardt, Bonn, Germany). The protein content was calculated by using a conversion factor of 6.25. Moisture was determined by drying the sample using an oven (Qualivac, Greenfield Oldham, UK) until reaching a constant weight (at $100{ }^{\circ} \mathrm{C}$ for 18 hours) and ash by incineration in a muffle furnace (Carbolite, Bamford Sheffield, England) at $550{ }^{\circ} \mathrm{C}$ for 4 hours. Lipid content was determined according to the Bligh and Dyer method (Bligh and Dyer, 1959). All analyses were performed in triplicate. 


\subsection{Extraction of gelatine}

Different pre-treatment methods were used to extract gelatines from mackerel and blue whiting bones.

\subsubsection{Pre-treatment}

\subsubsection{Chemical pre-treatment:}

Bones (250 g) used for gelatine extraction were treated with $0.1 \mathrm{~N} \mathrm{NaOH}$ at a ratio of $1 / 3(\mathrm{w} / \mathrm{v})$ for $30 \mathrm{~min}$ and this step was repeated 3 additional times to eliminate non-collagenous proteins and fat.

\subsubsection{Enzymatic pre-treatment:}

Fish bones (250 g) were mixed with $0.1 \mathrm{M}$ potassium phosphate buffer (pH 8) at a ratio of $1 / 3(\mathrm{w} / \mathrm{v})$ then heat treated in a microwave oven model R-244 (Sharp Electronics Ltd, Uxbridge, UK) for 5 min to inactivate the endogenous enzymes. After air cooling, Flavourzyme or Alcalase were added at an enzyme/substrate ratio of $0.1 \%(\mathrm{v} / \mathrm{w})$. The bones were hydrolysed for $4 \mathrm{~h}$ at $50{ }^{\circ} \mathrm{C}$ with continuous shaking at 150 rpm using a Gallenkamp orbital incubator (AGB, Dublin, Ireland). After hydrolysis the samples were heat treated in the microwave oven for $5 \mathrm{~min}$ to inactivate the enzymes. The mixture was allowed to cool down and filtered through a $1 \mathrm{~mm}$ pore size sieve to separate the bones from the protein hydrolysates. The clean bones were collected and demineralised.

\subsubsection{Demineralisation and gelatine extraction}

Fish bones were demineralised at room temperature for 18 hours using $0.25 \mathrm{~N}$ $\operatorname{HCl}(1 / 3, w / v)$. The demineralised bones were washed under running water from a tap to remove the acid. 
148

\subsubsection{Gelatine extraction}

The pre-treated bones were mixed with distilled water (at a ratio of $1 / 3, \mathrm{w} / \mathrm{v}$ ) and gelatine was extracted in a water bath at $45{ }^{\circ} \mathrm{C}$ for 18 hours. All extraction steps were done with continuous stirring at $150 \mathrm{rpm}$. Extracted gelatine was filtered using a Whatman No.4 filter paper (Whatman, Maidenstone, England). Gelatine was then evaporated under vacuum at $45{ }^{\circ} \mathrm{C}$ using a Büchi Rotavapor model R-210 fitted with a Büchi temperature-controlled water bath model B-491 and Büchi vacuum system model V-700 (Büchi UK Ltd., Oldham, UK), freeze dried (Labconco corporation, Kansas City, MO, USA) and ground. Gelatine extraction was done in triplicate for each fish species and repeated for 3 batches. Gelatine extraction yield was calculated as g of dry gelatine per $100 \mathrm{~g}$ of bones.

\subsection{Protein pattern of fish gelatines}

The electrophoresis procedure was carried out according to the method described by Khiari et al. (2011). Gelatine solutions (5 mg/mL) were prepared in distilled water at $60{ }^{\circ} \mathrm{C}$ and then diluted to a final concentration of $2 \mathrm{mg} / \mathrm{mL}$ with sample buffer containing $\beta$-mercaptoethanol (Sigma, Dublin, Ireland). Gelatine samples were heated to $85{ }^{\circ} \mathrm{C}$ for $10 \mathrm{~min}$ to denature the proteins. Samples and molecular weight marker $(10 \mu \mathrm{L}$ each) were loaded onto SDS-PAGE having a $4 \%$ stacking gel and 10\% resolving gel according to Laemmli (1970), the analysis was run in an Atto Dual Mini-slab Size Electrophoresis System AE-6450 (Atto Corporation, Tokyo, Japan) at a constant current of $25 \mathrm{~mA} / \mathrm{gel}$. Protein bands were stained with Coomassie Brilliant Blue R250. The gel was de-stained using a mixture of isopropanol, acetic acid and distilled water (12:10:78, v/v/v). 
174 mixture of six proteins: bovine carbonic anhydrase (29 kDa), egg albumin (45 kDa), 175 bovine albumin $(66 \mathrm{kDa})$, phosphorylase $\mathrm{B}$ from rabbit $(97.4 \mathrm{kDa}), \beta$-galactosidase 176 from E. coli (116 kDa) and myosin from rabbit muscle (200 kDa).

177

178

\subsection{Amino acids analysis}

The amino acid profile of gelatines was determined according to the method described by Khiari et al. (2011). Briefly, $10 \mu \mathrm{g}$ of gelatine were subjected to hydrolysis for $24 \mathrm{~h}$ at $110{ }^{\circ} \mathrm{C}$, with $6 \mathrm{M} \mathrm{HCl}$ containing $0.1 \%$ phenol in vacuumsealed hydrolysis vials. Norleucine (Sigma, Madrid, Spain) was added as an internal standard. The amino acid composition was analysed using a cation exchange Biochrom 20 amino acid analyzer (Pharmacia Biotech, Ltd., Cambridge, England) with postcolumn derivatisation with ninhydrin. All amino acids were detected at an absorbance of $570 \mathrm{~nm}$, except for proline and hydroxyproline which were measured at $440 \mathrm{~nm}$. Tryptophan and cysteine are completely lost by acid hydrolysis whereas methionine can be destroyed to varying degrees (Lourenço et al., 2002). Cysteine was determined as cysteic acid by oxidation of the protein with formic acid prior to hydrolysis, according to Hirs (1967). Results were averaged and presented as grams (g) per $100 \mathrm{~g}$ amino acids. The amino acid analysis was done in the Service of Protein Chemistry at the Centro de Investigaciones Biologicas (CSIC, Madrid).

\subsection{Protein solubility}

The effect of $\mathrm{pH}$ and ionic strength on the solubility of gelatines was determined according to the method of Montero et al. (1991), with some modifications. 


\subsubsection{Effect of pH on gelatine solubility}

Gelatine samples were first dissolved in distilled water to a final concentration of $0.3 \%$ (w/v, protein content). Eight $\mathrm{mL}$ of the gelatine solutions were added to a glass test tube and the $\mathrm{pH}$ was adjusted ranging from 2.0 to 12.0 with either $1 \mathrm{M} \mathrm{HCl}$ or $1 \mathrm{M} \mathrm{NaOH}$ using an Orion pH meter Model 420A (Orion Research Inc, Beverly, MA. USA). The $\mathrm{pH}$ meter was calibrated at $\mathrm{pH} 4.0,7.0$ and 10.0 before the analysis. The final volume was then adjusted to $10 \mathrm{~mL}$ by distilled water having the same $\mathrm{pH}$ as the gelatine solution. Samples were centrifuged at $9,000 \times \mathrm{g}$ for $15 \mathrm{~min}$ at $5{ }^{\circ} \mathrm{C}$. Protein content of the clear supernatant was determined according to the Biuret assay as described by Gornall et al. (1949) and using bovine serum albumin (BSA, SigmaAldrich, Inc., Dublin, Ireland) as a reference protein on a weight basis. Relative solubility was calculated in comparison with that obtained at the $\mathrm{pH}$ giving the highest solubility.

\subsubsection{Effect of $\mathrm{NaCl}$ on gelatine solubility}

Gelatines were dissolved in $50 \mathrm{mM}$ potassium phosphate buffer at $\mathrm{pH} 7.5$ to a final concentration of $0.6 \%$ (w/v, protein content). Five $\mathrm{mL}$ of gelatine solution were mixed with $5 \mathrm{~mL}$ of $\mathrm{NaCl}$ in $50 \mathrm{mM}$ phosphate buffer at $\mathrm{pH} 7.5$ at various concentrations $(0,2,4,6,8,10$ and $12 \%(\mathrm{w} / \mathrm{v}))$. The mixture was stirred continuously using a magnetic-stirrer device for $30 \mathrm{~min}$ at $5{ }^{\circ} \mathrm{C}$, followed by centrifugation at $9,000 \times \mathrm{g}$ for $15 \mathrm{~min}$ at $5^{\circ} \mathrm{C}$. Protein content of the clear supernatant was determined as described above. Relative solubility was calculated in comparison with that obtained at the $\mathrm{NaCl}$ concentration giving the highest solubility. 


\subsection{Foaming properties}

Foaming properties including foaming capacity (FC) and foam stability (FS) were determined by the method of Fernandez \& Macarulla (1997) with minor modifications. Gelatine solutions were prepared in $50 \mathrm{mM}$ phosphate buffer at $\mathrm{pH} 7.5$ to a final concentration of $0.3 \%(\mathrm{w} / \mathrm{v}$, in protein content). Five $\mathrm{mL}$ of each sample 231 were homogenized with an Ultra-Turrax homogenizer, model T 25 (IKA Works, Inc. 232 Staufen, Germany) at 23,000 rpm for $1 \mathrm{~min}$. FC was calculated as the percent increase 233 in volume of the protein dispersion upon mixing, while FS was estimated as the 234 percentage of foam remaining after $15 \mathrm{~min}$.

\subsection{Emulsifying properties}

The emulsifying properties of gelatine samples were determined by the method of Pearce \& Kinsella (1978) with some modifications. Different concentrations of gelatine solution were used. Gelatines were first dissolved in $50 \mathrm{mM}$ potassium phosphate buffer containing $0.3 \mathrm{M} \mathrm{NaCl}$ at $\mathrm{pH} 7.5$ to the final 241 concentration of $0.05,0.1$ or $0.2 \%(\mathrm{w} / \mathrm{v}$, in protein content). Then $2.0 \mathrm{~mL}$ of 242 commercial sunflower oil was mixed with $8.0 \mathrm{~mL}$ of each gelatine solution. The 243 mixture was vortexed in a plastic tube at $25^{\circ} \mathrm{C}$ and homogenized at $23,000 \mathrm{rpm}$ for 1 244 minute. An aliquot $(50 \mu \mathrm{L})$ of emulsion was diluted in $5 \mathrm{~mL}$ sodium dodecyl sulfate 245 (SDS) solution (0.1\%, w/v) and the absorbance was measured at $500 \mathrm{~nm}$ (Milton Roy 246 Spectonic 1201, Rochester, NY, USA). To estimate the emulsion stability, the 247 emulsions were left for $15 \mathrm{~min}$ at $25{ }^{\circ} \mathrm{C}$ and then $50 \mu \mathrm{L}$ of the emulsion were diluted 248 in $5 \mathrm{~mL}$ SDS solution $(0.1 \%, \mathrm{w} / \mathrm{v})$ and the absorbance was measured at $500 \mathrm{~nm}$. The 249 emulsifying activity and emulsion stability were expressed as indexes. 
EAI $\left(\mathrm{m}^{2} / \mathrm{g}\right)$ was defined as:

$$
\operatorname{EAI}\left(\mathrm{m}^{2} / \mathrm{g}\right)=\frac{2 \times 2.303}{C \times \phi \times 10^{4}} \times A_{500} \times \text { Dilution }
$$

Where; $A_{500}$ represents the absorbance at $500 \mathrm{~nm}, \mathrm{C}$ the protein concentration $(\mathrm{g} / \mathrm{mL})$ before emulsification and $\Phi$ the oil volume fraction (v/v) of the emulsion (i.e. the volume of emulsion droplets divided by the total volume of the emulsion, $\Phi=0.2$ ).

ESI (\%) was calculated as the ratio of the turbidity measured at $500 \mathrm{~nm}$ of the emulsion at time zero $\left(\mathrm{A}_{0}\right)$ and after $15 \min \left(\mathrm{A}_{15}\right)$ (Agyare et al., 2009).

$$
\operatorname{ESI}(\%)=100 \times \frac{A_{15}}{A_{0}}
$$

\subsection{Statistical analyses}

ANOVA (Multifactor and one-way) was used to find differences between treatments. Means were compared by significant difference (LSD) test, at a significance level of $\mathrm{p}<0.05$ using the Statgraphics Centurion $\mathrm{XV}$ software (version 15.1.02; StatPoint, Inc., Warrenton, VA, USA). Three independent trials were carried out.

\section{Results and discussion}

\subsection{Characterisation of fish bones and gelatine extraction yield}

Mackerel and blue whiting bones had similar protein (19.8 and 19.5\%, respectively) and moisture (64.9 and 64.2\%, respectively) contents. The ash content was considerably high for both fish bones (8.9 and 16.0\% for mackerel and blue whiting, respectively) mainly due to the high content of minerals. The fat content of mackerel bones was significantly $(\mathrm{p}<0.05)$ higher than blue whiting bones $(5.5$ and 
$0.8 \%$, respectively), which could be due to the variation among the species (fatty and lean fish).

The gelatine extraction yields varied depending on the pre-treatment used for mackerel and blue whiting bones (Table 1). Regardless of fish, gelatine extracted from chemically pre-treated bone, showed the lowest yield. Yields of 2.5 and 1.0\% were observed for mackerel and blue whiting respectively. Bones pre-treated enzymatically generated significantly $(\mathrm{p}<0.05)$ highest yields $(\sim 3.9$ and $1.8 \%$, for mackerel and blue whiting, respectively).

\subsection{Protein pattern of fish gelatines}

The electrophoretic (SDS-PAGE) profiles of the various gelatine preparations are shown in Figure 1.

The gel electrophoresis of chemically pre-treated fish bone gelatines (Figure 1 A \& B, lane 4) showed the presence of the three bands (one $\beta$ chain and two $\alpha$ chains). These three chains are characteristics of type I gelatine. The $\beta$ chain seems to be lower or entirely absent in bone gelatines extracted after the enzymatic pre-treatment (Figure 1 A \& B, lane $2 \& 3$ ), which could be due to the combined effect of enzymatic and chemical hydrolysis of the gelatines as a consequence of the demineralisation step. The presence of low molecular weight proteins was observed in gelatines extracted after the enzymatic pre-treatment. This may indicate a partial hydrolysis of gelatine during extraction (Giménez et al., 2005). 


\subsection{Amino acid profile}

The amino acid composition of gelatine from mackerel and blue whiting bones, expressed as percentage of total amino acid, is shown in Table 2. Different profiles were observed for fish bone gelatines depending on the pre-treatment. Mackerel bone gelatine, pre-treated with sodium hydroxide, had high glycine content (21.3\%). Gelatines extracted after the enzymatic pre-treatment of mackerel bones, showed significantly different amino acid profile. The glycine content was half of that observed for chemically pre-treated bone gelatines ( 11.5\%). Blue whiting bone gelatines, pre-treated with sodium hydroxide and Alcalase, had similar glycine content ( 20\%). However, lower glycine content was observed with Flavourzyme pre-treated blue whiting bone gelatines (17\%).

For both fish, significant $(\mathrm{p}<0.05)$ differences among the content of hydrophobic amino acids (Ala, Val, Ile, Leu, Met, Phe, Tyr and Cys) were observed for enzymatically pre-treated bone gelatines compared to chemically pre-treated bone gelatines. Low content of imino acids (proline and hydroxyproline) were observed for both fish bone gelatines, pre-treated enzymatically, compared to chemically pretreated fish bone gelatines. The imino acid content of chemically pre-treated bone gelatines was similar to that observed for Japanese sea bass caudal fin (Nagai, 2004), black drum (Pogonia cromis) and sheepshead seabream (Archosargus probatocephalus) bone collagens (Ogawa et al., 2003). The difference among proline and hydroxyproline contents of mackerel bone gelatines may affect the rheological properties of the gelatines. Gelatines with low proline and hydroxyproline level usually show lower melting point and weaker gel network (Gilsenan \& Ross-Murphy, 2000; Johnston-Banks, 1990). 
329 but cysteine was present in low levels. This may indicate some contaminations by 330 non-collagenous protein (Morimura et al., 2002).

\subsection{Protein solubility}

The effect of $\mathrm{pH}$ and $\mathrm{NaCl}$ on the relative solubility of gelatines from mackerel and blue whiting bones are shown in Figure 2.

All the gelatines, regardless of the pre-treatment used, showed similar $\mathrm{pH}$ behaviour. The solubility was higher at low $\mathrm{pH}$, with a maximum at $\mathrm{pH} 2$. The lowest solubility was observed close to neutral pH (Figure 2 A \& B). Similar results were also reported by Aewsiri et al. (2008) for gelatines from precooked tuna fin.

The effect of $\mathrm{NaCl}$ on the relative solubility is depicted in Figure 2 (C \& D). In general, the solubility of gelatines decreased gradually with increasing concentration. The decrease in solubility with the increase of $\mathrm{NaCl}$ concentration is probably due to the increase of the hydrophobic interactions and to the competition of ionic salts for water (Vojdani, 1996).

The higher solubility of gelatines, from both fish bones pre-treated enzymatically, compared to those pre-treated chemically could be due to the presence of lower molecular weight peptides formed during the extraction process (enzymatic hydrolysis and demineralisation step). The hydrolysis generally cleaves peptides with more polar residues that may interact with water molecule through hydrogen bonds and results in an increase in solubility (Gbogouri et al., 2004).

\subsection{Foaming capacity and stability}

Foams are complex two-phase colloidal systems which contain at least a continuous liquid phase and a gas phase dispersed as bubbles or air cells. The 
354

properties of foams determine their industrial applications. In the food industry, the determination of foaming properties has a significant impact on the processing and the quality of some products (Exerowa \& Kruglyakov, 1998).

The foaming capacity (FC) of gelatines, extracted from mackerel and blue whiting bones, varied significantly $(\mathrm{p}<0.05)$ depending on the source and the pretreatment. Regardless of the pre-treatment, gelatines from blue whiting bones showed higher FC than mackerel bone gelatines. Mackerel bone gelatines showed similar values for FC ( $\sim 38 \%$, Figure 3 A) with no significant ( $p>0.05)$ differences between pre-treatments. Gelatines extracted from blue whiting bones, after enzymatic pretreatment, had significantly $(\mathrm{p}<0.05)$ higher FC than chemically pre-treated bones (Figure 3 B). All mackerel bone gelatines, regardless of the pre-treatment used had very high foaming stability (Figure $3 \mathrm{C}$ ). Blue whiting bone gelatines had lower FS than mackerel bone gelatines. The chemical pre-treatment of blue whiting bones resulted in gelatines with significantly $(\mathrm{p}<0.05)$ lower FS than enzymatic pretreatment.

Foaming properties (foaming capacity and stability) of a protein, including gelatine, might be influenced by the source, intrinsic properties, the compositions and conformations of the protein in solution (Wilde \& Clark, 1996; Zayas, 1997). The process of foam formation depends largely on the protein adsorption kinetics at the air-water interface (Phillips et al., 1994). The higher FC observed with enzymatically pre-treated bone gelatines may be due to the higher amount of hydrophobic amino acid residues (Ala, Val, Ile, Leu, Met, Phe, Tyr and Cys) compared to chemically pretreated bone gelatines (Table 2). The foaming agent, having an amphiphilic property, adsorbs at the air-water interface and orients itself in such a way that the lipophilic group orients towards the non-polar phase and the hydrophilic group towards the 
aqueous phase. This phenomenon reduces the surface tension allowing the formation of the foam (Liceaga-Gesualdo \& Li-Chan, 1999). The lower FS observed with chemically pre-treated mackerel and blue whiting bone gelatines compared to those extracted after the enzymatic pre-treatment of bones, could be due to the lower percentage of negatively charged amino acids (Asp and Glu). On average, the enzymatic pre-treated bone gelatines had 21\% negatively charged amino acids compared to $16 \%$ from chemically pre-treated bone gelatines. Higher content of negatively charged amino acids, observed with enzymatically pre-treated bone gelatines, may have prevented the neutralisation of charge in gelatine molecules and enhanced the FS.

\subsection{Emulsifying capacity and stability}

Emulsions are a major component of many foods and their properties (emulsifying capacity and stability) play an important role in the formulation of food products (Spyropoulos et al., 2011). Emulsion activity index (EAI) and emulsion stability index (ESI) for gelatines from mackerel and blue whiting bones at different protein concentrations $(0.05,0.1$ and $0.2 \%)$ are shown in Table 3.

\subsubsection{Emulsifying capacity}

The emulsifying activity index (EAI), a measurement of the area of interface stabilized per unit weight of protein $\left(\mathrm{m}^{2} / \mathrm{g}\right)$ relates to the ability of a protein to coat an interface (Pearce \& Kinsella, 1978). The results showed that the increase of the concentration of gelatine solution decreased the emulsifying activity (EAI). Similar results were reported by Binsi et al. (2009) for gelatine from skin of bigeye snapper. The protein concentration is an important parameter that affects the emulsifying activity. Low protein concentration favours higher EAI, due to the ability of the 
405

protein to diffuse and adsorb at the oil-water interface (Cheftel et al., 1985). While at high protein concentration, the diffusion is limited as a result of the activation energy barrier (Phillips, 1981).

For all the concentrations studied (0.05, 0.1 and $0.2 \%)$, gelatines extracted from mackerel and blue whiting bones after pre-treatment with Alcalase and Flavourzyme showed significantly $(\mathrm{p}<0.05)$ highest EAI, while the chemical pretreatment gave gelatines with the lowest EAI (Table 3). This possibly resulted from the difference in the intrinsic properties, composition and conformation among the different gelatines (Cheftel et al., 1985). Mechanisms of the emulsification process of gelatines are correlated to the adsorption ability at the surface of freshly formed oil droplets during homogenization and formation of a protective membrane that prevents droplets coalescence. According to Rahali et al. (2000), the degree of insertion of peptides in the interfacial layer mostly depends on the alternative distribution of hydrophobic and charged amino acids. The flexibility of protein (or peptide) structure may be an important structural factor governing the emulsification (Kato et al., 1985). It is also known that protein solubility plays an important role in emulsification because rapid migration and adsorption at the interface are critical (Chobert et al., 1988).

\subsubsection{Emulsifying stability}

For all gelatines, regardless of the source and the pre-treatment, a positive correlation between the protein concentration and the ESI was found (increasing the concentration of gelatine solutions increased the ESI). Similar results were previsouly observed for whey proteins (Hung \& Zayas, 1991). High protein concentrations result 
429 in higher viscosity of the dispersion. This usually leads to a better emulsion stability 430 probably by reducing the coalescence rate (Sajjadi, 2007). showed significantly $(\mathrm{p}<0.05)$ higher ESI compared to those extracted after the 433 chemical pre-treatment (Table 3). As discussed before, gelatines from mackerel and 434 blue whiting bones, pre-treated with Flavourzyme and Alacalse, had significantly 435 higher hydrophobic amino acid residues. According to Giménez et al. (2009), a higher content in hydrophobic amino acid residues results in an effective distribution of hydrophilic/hydrophobic amino acids which leads to an improvement of the 438 emulsifying properties of gelatines. Hence, the higher content of hydrophobic amino 439 acid residues, observed with enzymatically pre-treated bone gelatines, may have resulted in better EAI and ESI in comparison to chemically pre-treated bone gelatines.

\section{Conclusion}

The composition and the functional properties of mackerel and blue whiting 443 bone gelatines were affected by the pre-treatment used in the extraction process. The 444 enzymatic pre-treatment of fish bones produced gelatines with higher content of 445 hydrophobic amino acid residues. The presence of these amino acids had a positive 446 effect on the functional properties of the gelatines. In general, higher foaming and 447 emulsifying properties were observed with enzymatically pre-treated bone gelatines.

\section{Acknowledgements}

This work was conducted with the financial support from the Irish government

451 under FIRM 2006. The authors would like to acknowledge their support. Many thanks 452 go to Mr. John Fagan from BIM and Donegal Seafood for providing the fish. 


\section{References}

455 Aewsiri, T., Benjakul, S., Visessanguan, W. and Tanaka, M. (2008). Chemical 456 compositions and functional properties of gelatin from pre-cooked tuna fin. 457 International Journal of Food Science and Technology. 43, 685-693.

458

459 Agyare, K.K., Addo, K. and Xiong, L.Y. (2009). Emulsifying and foaming properties 460 of transglutaminase-treated wheat gluten hydrolysate as influenced by $\mathrm{pH}$, 461 temperature and salt. Food Hydrocolloids. 23, 72-81.

462

463

AOAC (2000). Association of Official Analytical Chemist. In: Official Methods of 464 Analysis of AOAC International, Horwitz, W. (Ed.). Association of Official Analytical 465 Chemists International: Gaithersburg, MD.

466

Aspmo, S.I. Horn, S.J. and Eijsink, V.G.H. (2005). Enzymatic hydrolysis of Atlantic 468 cod (Gadus morhua L.) viscera. Process Biochemistry. 40,1957-1966.

469

Binsi, P.K., Shamasundar, B.A., Dileep, A.O., Badii, F. and Howell, N.K. (2009).

471 Rheological and functional properties of gelatin from the skin of Bigeye snapper 472 (Priacanthus hamrur) fish: Influence of gelatin on the gel-forming ability of fish 473 mince. Food Hydrocolloids. 23, 132-145.

474

475 Bligh, E.G. and Dyer, W.J. (1959). A rapid method for total lipid extraction and 476 purification. Canadian Journal of Biochemistry and Physiology. 37, 911-917. 
478 Cheftel, J.C., Cuq, J.L. and Lorient, D. (1985). In: Food chemistry (2 ${ }^{\text {nd }}$ edition),

479 Fennema, O.R. (Ed.). Marcel Dekker, Inc., New York. USA. 245-369.

480

481 Chobert, J.M., Bertrand-Harb, C. and Nicolus, M.G. (1988). Solubility and 482 emulsifying properties of caseins and whey proteins modified enzymatically by 483 trypsin. Journal of Agricultural and Food Chemistry. 36, 883-892.

484

485 Collette, B.B. and Nauen, C.E. (1983). FAO species catalogue. Vol. 2. Scombrids of 486 the world. An annotated and illustrated catalogue of tunas, mackerels, bonitos and 487 related species known to date. FAO Fisheries Synopsis, 125, 58-59.

488

489 Council Directive (1999). Council Directive 1999/31/EC of 26 April 1999 on the 490 landfill of waste. Official Journal of the European Communities. L 182, 16/07/1999.

492 Exerowa, D. and Kruglyakov, P. (1998). Foam and foam films: theory, experiment, 493 application (Studies in interface science). Elsevier, Amsterdam. 656-737.

494

495 FAO (2009). Yearbooks of Fisheries Statistics. Food Agriculture Organization of the 496 United Nations, Rome.

497

498 Fernandez, Q.A. and Macarulla, M.T. (1997). Composition and functional properties 499 of protein isolates obtained from commercial legumes grown in northern Spain. Plant 500 Foods for Human Nutrition. 51, 331-342. 
502 Gbogouri, G. A., Linder, M., Fanni, J. and Parmentier, M. (2004). Influence of 503 hydrolysis degree on the functional properties of salmon by-products hydrolysates. 504 Journal of Food Science. 69, 615-622.

506 Gilsenan, P.M. and Ross-Murphy, S.B. (2000). Rheological characterisation of 507 gelatins from mammalian and marine sources. Food Hydrocolloids. 14, 191-196.

508

509 Giménez, B., Alemán, A., Montero, P. and Gómez-Guillén, M.C. (2009). Antioxidant 510 and functional properties of gelatin hydrolysates obtained from skin of sole and squid. 511 Food Chemistry. 114, 976-983.

513 Giménez, B., Turnay, J., Lizarbe, M.A., Montero, P. and Gómez-Guillén, M.C. 514 (2005). Use of lactic acid for extraction of fish skin gelatine. Food Hydrocolloids. 19, $515941-950$.

516

517 Gornall, A.G., Bardawill, C.J. and David, M.M. (1949). Determination of serum 518 proteins by means of the biuret reaction. The Journal of Biological Chemistry. 177, $519 \quad 751-766$.

521 Hirs, C.H.W. (1967). Determination of cystine as cysteic acid. Methods in 522 Enzymology. 11, 59-62.

524 Hung, S.C. and Zayas, J.F. (1991). Emulsifying capacity and emulsion stability of 525 milk proteins and corn germ protein flour. Journal of Food Science. 56, 1216-1223. 
527 Johnston-Banks, F.A. (1990). Gelatin. In: Food gels, Harris, P. (Ed.). Elsevier 528 Applied Science Publishers, London, 233-289.

529

530 Kato, A., Fujishige, T., Matsudomi, N. and Kobayashi, K. (1985). Determination of 531 emulsifying properties of some proteins by conductivity measurements. Journal of 532 Food Science. 50, 56-62.

533

534 Khiari, Z., Rico, D., Martin-Diana, A.B. and Barry-Ryan, C. (2011). The extraction of 535 gelatin from mackerel (Scomber scombrus) heads with the use of different organic 536 acids. Journal of FisheriesSciences.com. 5, 52-63.

537

538 Kim, S.K. and Mendis, E. (2006). Bioactive compounds from marine processing 539 byproducts - A review. Food Research International. 39, 383-393.

540

541 Kittiphattanabawon, P., Benjakul, S., Visessanguan, W., Nagai, T. and Tanaka, M. 542 (2005). Characterisation of acid-soluble collagen from skin and bone of bigeye 543 snapper (Priacanthus tayenus). Food Chemistry. 89, 363-372.

544

545 Laemmli, U.K. (1970). Cleavage of structural proteins during the assembly of the 546 head of bacteriophage T4. Nature. 227, 680-685.

547

548 Liceaga-Gesualdo, A.M. and Li-Chan, E.C.Y. (1999). Functional properties of fish 549 protein hydrolysate. Journal of Food Science. 64, 1000-1004. 
551 Lourenço, S.O., Barbarino, E., De-Paula, J.C., Pereira, L.O. and Marquez, Y.M.L. 552 (2002). Amino acid composition, protein content and calculation of nitrogen-to553 protein conversion factors for 19 tropical seaweeds. Phycological Research. 50, 233554241.

555

556 Montero, P., Jimenez-Colmenero, F. and Borderias, J. (1991). Effect of pH and the 557 presence of $\mathrm{NaCl}$ on some hydration properties of collagenous material from trout 558 (Salmo irideus Gibb) muscle and skin. Journal the Science of Food and Agriculture. $559 \quad 54,137-146$.

560

561 Morimura, S., Nagata, H., Uemura, Y., Fahmi, A., Shigematsu, T. and Kida, K. 562 (2002). Development of an effective process for utilization of collagen from livestock 563 and fish waste. Process Biochemistry. 37, 1403-1412.

565 Nagai, T., Izumi, M. and Ishii, M. (2004). Fish scale collagen. Preparation and partial 566 characterization. International Journal of Food Science and Technology, 39, 239-244. 567

568 Nawar, W.W. (1985). Lipids. In: Food chemistry (2 ${ }^{\text {nd }}$ edition), Fennema, O.R. (Ed.). 569 Marcel Dekker Inc., New York. 139-244.

570

571 Ogawa, M., Moody, M.W., Portier, R.J., Bell, J., Schexnayder, M. and Losso, J.N. 572 (2003). Biochemical properties of black drum and sheepshead seabream skin 573 collagen. Journal of Agricultural and Food Chemistry. 51, 8088-8092. 
575 Pearce, K.N. and Kinsella, J.E. (1978). Emulsifying properties of proteins. Evaluation 576 of a turbidimetric method. Journal of Agricultural and Food Chemistry. 26, 716-721.

578 Phillips, L.G., Whitehead, D.M. and Kinsella, J.E. (1994). Structure-function 579 properties of food proteins. Academic Press, San Diego, CA, 131-152.

580

581 Phillips, M.C. (1981). Protein conformation at liquid interfaces and its role in 582 stabilizing emulsions and foams. Food Technology. 35, 50-57.

584 Rahali, V., Chobert, J.M., Haertle, T. and Gueguen, J. (2000). Emulsification of 585 chemical and enzymatic hydrolysates of $\beta$-lactoglobulin: characterization of the 586 peptides adsorbed at the interface. Nahrung. 44, 89-95.

588 Regulation (EC) No.1774/2002 of the European Parliament and of the Council of 3 589 October 2002 laying down health rules concerning animal by-products not intended 590 for human consumption. Official Journal of the European Union. L273, 1-95.

591

592 Sajjadi, S. (2007). Formation of fine emulsions by emulsification at high viscosity or 593 low interfacial tension; A comparative study. Colloids and surfaces A: 594 physicochemical and engineering aspects. 299, 73-78.

596 Schrieber, R. and Gareis, H. (2007). Gelatine Handbook: Theory and industrial 597 practice. Wiley-VCH GmbH \& Co, Weinhem, Germany. 
599 Shahidi, F. (1994). Seafood processing by-products. In: Seafoods chemistry, 600 processing, technology and quality, Shahidi, F. and Botta, J.R. (Eds.). Blackie 601 Academic and Professional, London, 320-334.

602

603 Spyropoulos, F., Hancocks, R.D. and Norton, I.T. (2011). Food-grade emulsions 604 prepared by membrane emulsification techniques. Procedia Food Science. 1, 920605926.

606

607 Vojdani, F. (1996). Solubility. In: Methods of testing protein functionality $\left(1^{\text {st }}\right.$ 608 edition), Hall, G.M. (Ed.). St Edmundsbury Press, Bury St. Edmunds, UK. 11-60.

609

610 Wilde, P.J. and Clark, D.C. (1996). Foam formation and stability. In: Methods of 611 testing protein functionality (1 ${ }^{\text {st }}$ edition), Hall, G.M. (Ed.). St Edmundsbury Press, 612 Bury St. Edmunds, 110-152.

613

614 Zayas, J.F. (1997). Solubility of proteins. In: Functionality of proteins in food. 615 Springer-Verlag. Berlin, 6-22.

616

617

618

619

620

621

622

623 
626 Figure 1 SDS-PAGE patterns of mackerel (A) and blue whiting (B) bone gelatines.

627 Lane 1: Molecular weight marker (MW. 30,000 - 200,000); lane 2: gelatine from bone 628 pre-treated with Flavourzyme; lane 2: gelatine from bone pre-treated with Alcalase; 629 lane 4: gelatine from bone pre-treated with $\mathrm{NaOH}$.

630

631

632

633

634

635

636

637

638

639

640

641

642

643

644

645

646

647

648 concentrations $(0.05,0.1$ and $0.2 \%)$.

\section{Table Captions}

Table 1 Yield of gelatine extraction.

Figure 2 Foaming capacity (FC) and stability (FS) of gelatines from mackerel (A \& C) and blue whiting (B \& D) bones extracted using different pre-treatments.

Figure 3 Relative solubility of gelatines from mackerel (A \& C) and blue whiting (B \& D) bones extracted using different pre-treatments. Solubility in the pH range $2-12$ (A \& B) and solubility as function of $\mathrm{NaCl}$ concentration (C \& D).

Table 2 Average amino acid composition (g/100 g amino acids) of gelatines extracted from mackerel and blue whiting bones using different pre-treatments.

649 
650

Khiari et al

651

652

653

654

655

656

Figure 1

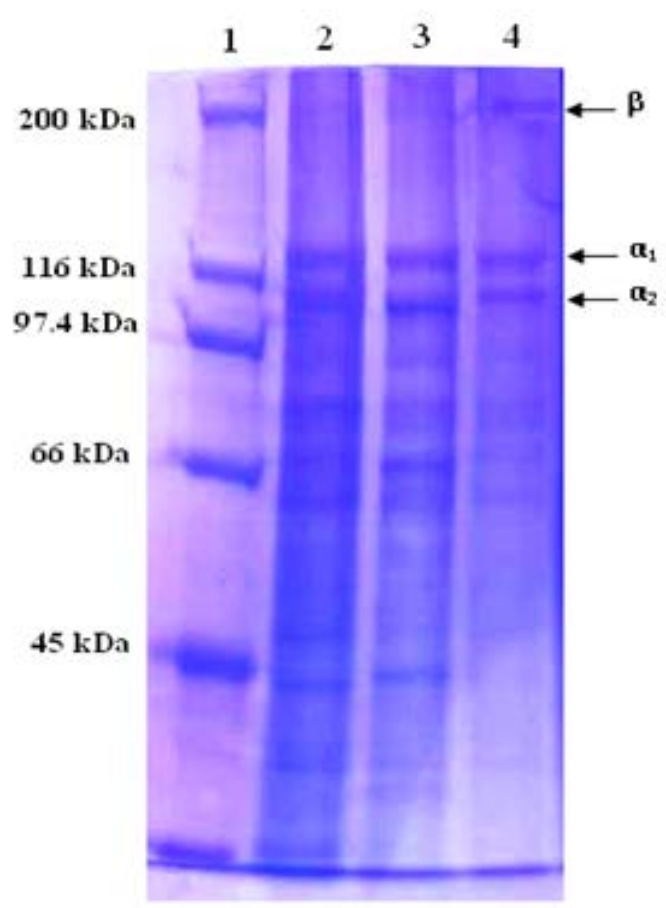

A

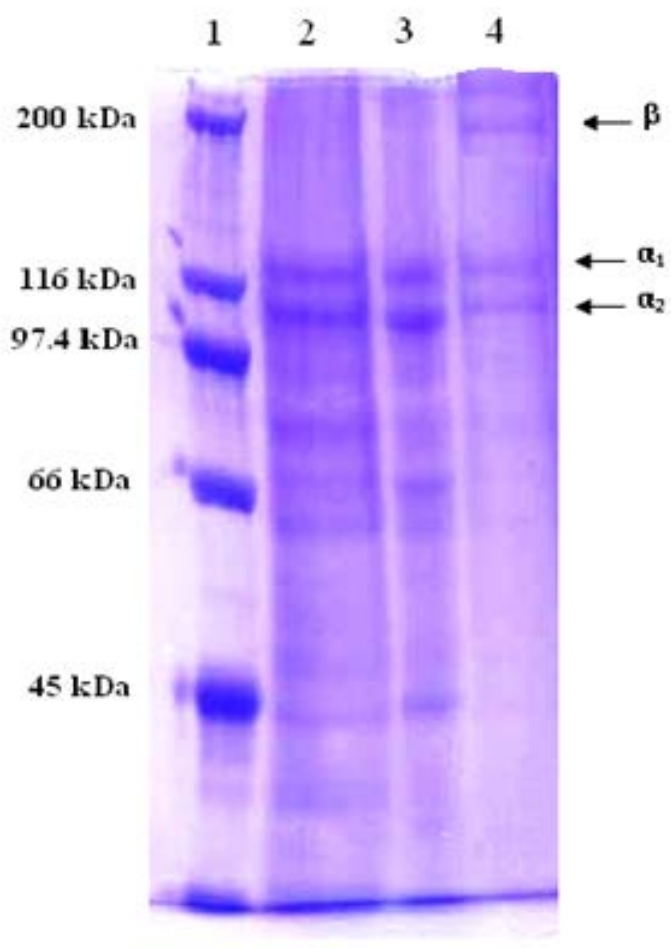

B

657

658

659 
660

661

662

663

664

665

666

667

668

669

670

671

672

673

674

675

676

677

678

679

680

681

682

683

684

685

686

687

688

689

690

691

692

693

694

85

Khiari et al

Figure 2

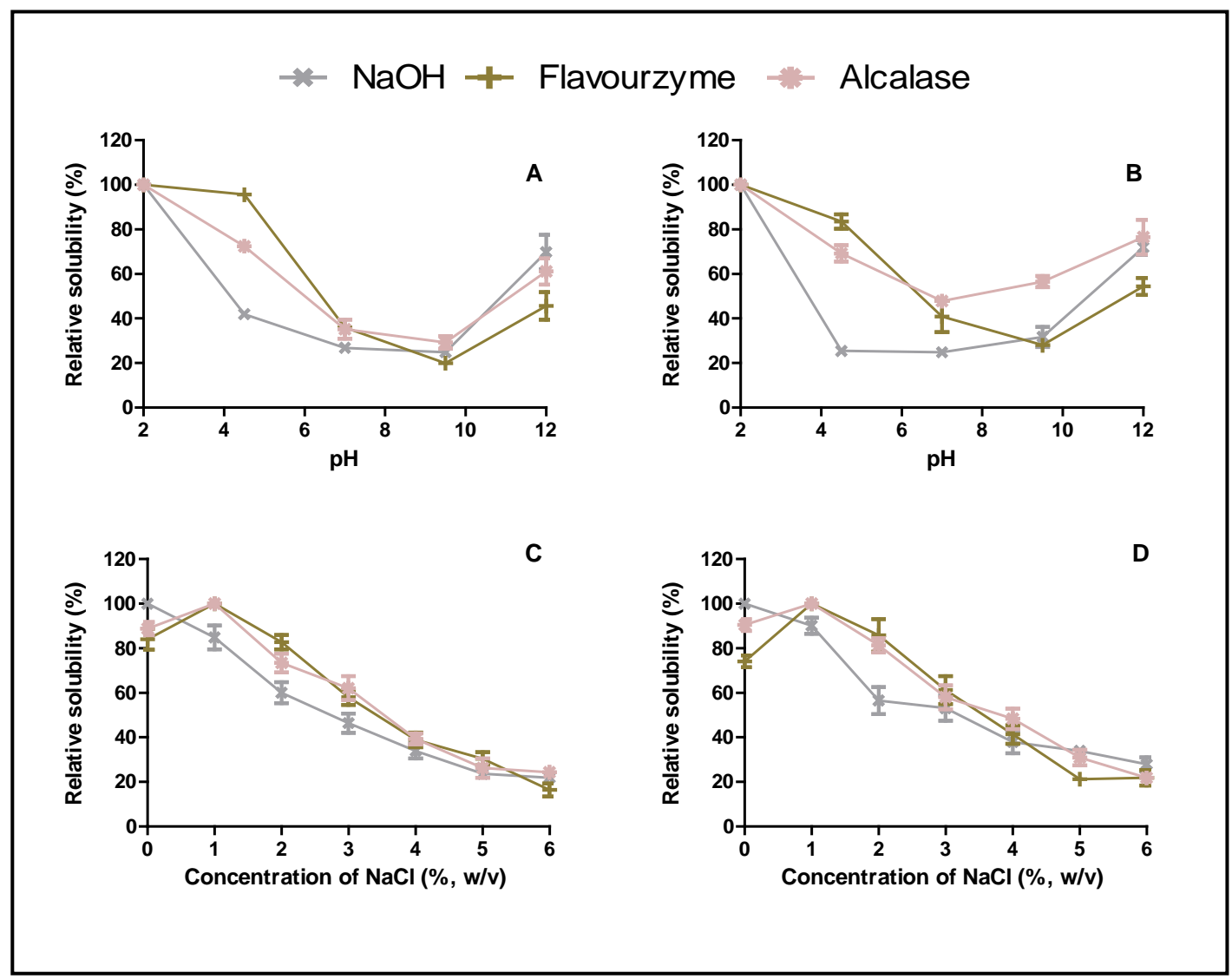

87 
Khiari et al

696

697

698

699

700

701

702

703

704

705

706

707

708

709

710

711

712

713

714

715

716

717

718

719

720

721

Figure 3
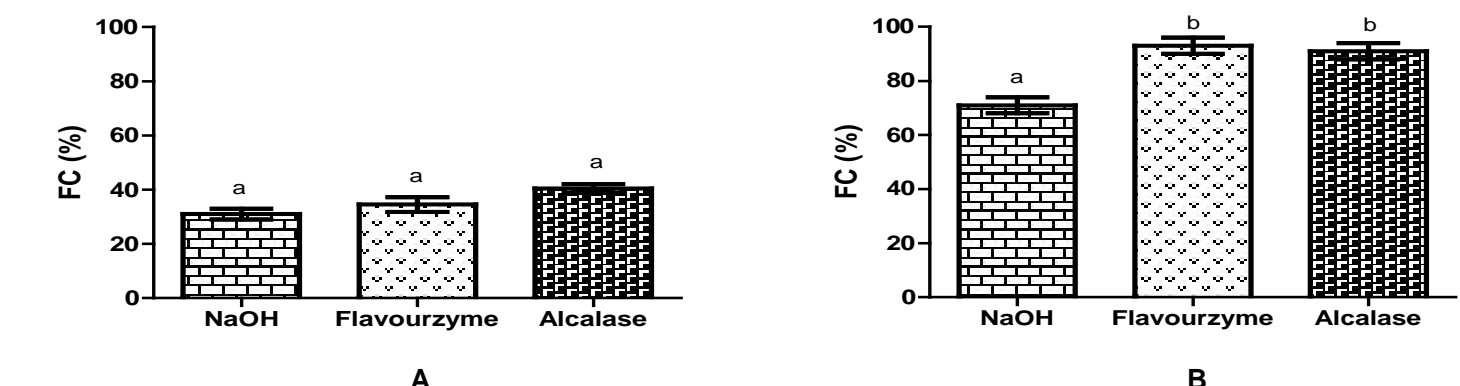

B
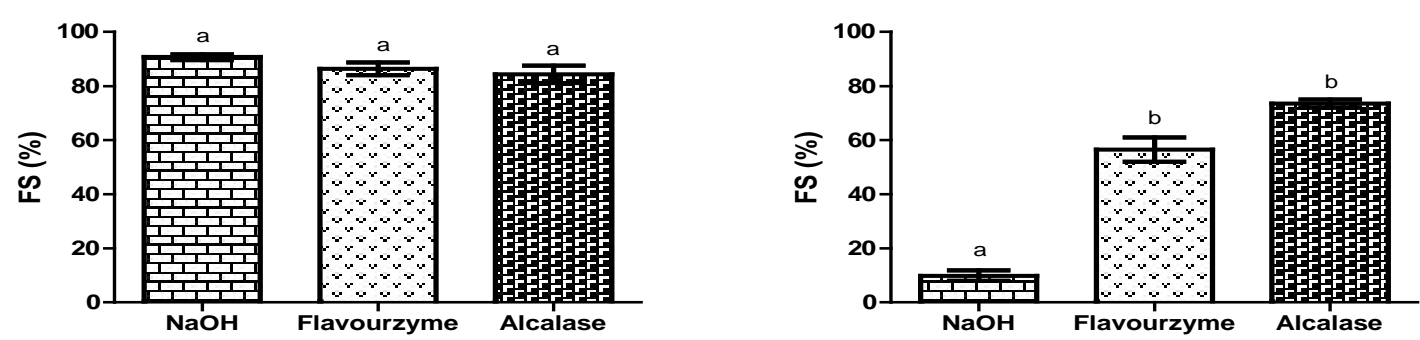

C

D

722

723

724

725

726

727

728

729

730

731

732

733

734

735

736

737

738

739

740

741 
Khiari et al

Table 1

745

Pre-treatment: NaOH: alkaline; Alcalase and Flavourzyme. Values are given as mean \pm standard deviation. Different lower case letters in the same column indicate significant $(\mathrm{p}<0.05)$ differences between pre-treatments. Different upper case letters in 760 the same row, within the same pre-treatment (i.e. chemical or enzymatic), indicate

761 significant $(\mathrm{p}<0.05)$ differences between fish species.

762 
Khiari et al

Table 2

\begin{tabular}{|c|c|c|c|c|c|c|}
\hline \multirow{3}{*}{$\begin{array}{l}\text { Amino } \\
\text { acids }\end{array}$} & \multicolumn{6}{|c|}{ Content (g/100 g amino acids) } \\
\hline & \multicolumn{3}{|c|}{ Mackerel } & \multicolumn{3}{|c|}{ Blue whiting } \\
\hline & $\mathrm{NaOH}$ & Alcalase & Flavourzyme & $\mathrm{NaOH}$ & Alcalase & Flavourzyme \\
\hline Asp & 6.1 & 8.1 & 7.8 & 6.5 & 8.7 & 8.4 \\
\hline Thr & 2.8 & 3.8 & 3.7 & 3.0 & 2.9 & 3.3 \\
\hline Ser & 4.8 & 4.6 & 4.4 & 5.6 & 5.3 & 5.4 \\
\hline Glu & 9.8 & 13.5 & 13.3 & 10.5 & 10.9 & 11.7 \\
\hline Gly & 21.3 & 11.4 & 11.6 & 20.7 & 20 & 17.3 \\
\hline Ala & 9.0 & 7.0 & 7.3 & 9.1 & 8.8 & 8.3 \\
\hline Cys & 0.8 & 1.2 & 1.2 & 0.1 & 0.2 & 0.2 \\
\hline Val & 2.3 & 4.0 & 3.7 & 2.3 & 2.5 & 2.8 \\
\hline Met & 2.1 & 2.6 & 2.6 & 2.4 & 2.5 & 2.7 \\
\hline Ile & 1.3 & 3.0 & 2.5 & 1.4 & 1.6 & 2.0 \\
\hline Leu & 3.7 & 6.2 & 6.0 & 2.9 & 3.4 & 4.1 \\
\hline Tyr & 1.1 & 2.7 & 2.3 & 0.7 & 1.1 & 1.5 \\
\hline Phe & 2.6 & 3.3 & 3.1 & 2.4 & 2.4 & 2.7 \\
\hline His & 1.2 & 2.3 & 2.3 & 1.6 & 1.6 & 1.8 \\
\hline Lys & 4.1 & 6.7 & 7.0 & 3.7 & 4.1 & 4.8 \\
\hline Arg & 8.4 & 7.3 & 7.5 & 8.6 & 8.8 & 8.4 \\
\hline Pro & 10.3 & 6.9 & 7.7 & 9.7 & 9.4 & 8.4 \\
\hline Нур & 8.3 & 5.4 & 6.0 & 8.5 & 5.7 & 6.1 \\
\hline
\end{tabular}

795

796

797

798 Pre-treatment: NaOH: alkaline; Alcalase and Flavourzyme. The amino acid

799 composition was performed in triplicate and data correspond to mean values.

800

801

802

803

804

805 


\section{$806 \quad$ Khiari et al}

807

Pre-treatment: $\mathrm{NaOH}$ : alkaline; Alcalase and Flavourzyme. Values are given as mean \pm standard deviation. Different lower case letters in the 